\title{
Establishing priorities for national communicable disease surveillance
}

\author{
Jo-Anne Doherty MSc for the ACE Subcommittee on Communicable Diseases*
}

$\mathrm{T}$ he federal government has collected information on communicable diseases since 1924, under the legislative authority of the Statistics Canada Act and the Health Canada Act $(1,2)$. Aggregate data on communicable diseases was initially collected and collated by The Dominion Bureau of Statistics (later changed to Statistics Canada), but this responsibility, with the exception of tuberculosis, was transferred to the Laboratory Centre for Disease Control (LCDC) in 1988. Responsibility for tuberculosis was subsequently transferred to the LCDC in 1995. Currently, information on communicable diseases under national surveillance is managed by the Division of Disease Surveillance within the Bureau of Infectious Diseases, LCDC.

The delivery of health care and public health services is identified in the Canadian Constitution as a provincial power. The federal government has powers over the provision of safe food and the importation of communicable diseases, and has the power to assist in a crisis such as an infectious disease outbreak.

Although communicable disease surveillance is carried out under provincial authority, coordination and monitoring occur at the federal level. Provincial and federal health authorities reach agreement on communicable disease surveillance by means of a joint committee called the Advisory Committee on Epidemiology (ACE) and its subcommittee on communicable diseases.

The Division of Disease Surveillance is frequently asked why all infectious diseases of general interest are not nationally notifiable. First, disease surveillance requires money, time and energy for health care providers, local health units, provinces, territories or Health Canada to report and collect data on every communicable disease. Second, it requires considerable time and effort to make a disease nationally notifi- able because every province and territory needs to go through the legislative or regulatory process of making the disease reportable within their jurisdictions. The process is managed by setting priorities to decide where to put the greatest effort. Criteria for priority setting should be explicit and measurable, and should minimize the influence of such factors as personal interest and political agendas. To the utmost degree possible, the criteria should be based on scientific evidence. Above all, "the challenge is to make the priority-setting process transparent and open to criticism and revision" (3).

Before 1987, there was no mechanism in place to evaluate newly emerging diseases and compare them with the diseases that were being reported. Accordingly, in 1987, ACE established a subcommittee on communicable diseases to develop a systematic process to determine which communicable diseases should be monitored at the national level. The subcommittee asked which diseases should be routinely monitored, how should they be monitored and whether they should be monitored at all. These are important questions that have led to a priority setting exercise with the following objectives: to ensure national surveillance of major infectious diseases that threaten the health of Canadians; to support the development and evaluation of programs that are currently in place and those which have been proposed; to ensure the participation of Canada in the global surveillance of specific health threats; and to determine the best use of human and financial resources in the prevention and control of communicable diseases.

The priority setting process involves several steps: establishing the criteria; subdividing each criterion into levels; assigning points to each level within each criterion; summing the points and assigning a total score to each disease; ranking the diseases from highest to lowest score; and determining a cut-off point that would allow the inclusion and exclusion of

*Members of the Advisory Committee on Epidemiology, Subcommittee on Communicable Diseases, 1997-1998: Drs Monique Douville-Fradet (Chair), Provincial Epidemiologist, Quebec City, Quebec; Andre Corriveau, Provincial Epidemiologist, Yellowknife, The Northwest Territories; Eric Young, Provincial Epidemiologist, Regina, Saskatchewan; John Waters, Provincial Epidemiologist, Edmonton, Alberta; Faith Stratton, Provincial Epidemiologist, St John's, Newfoundland; Kevin Forward (Representative of the Technical Advisory Committee [TAC]), Edmonton, Alberta Correspondence and reprints: Ms Jo-Anne Doherty, Division of Disease Surveillance, Bureau of Infectious Diseases, Laboratory Centre for Disease Control, Health Canada, Tunney's Pasture, Postal Locator 0603E1, Ottawa, Ontario K1A OL2. Telephone 613-946-2328, fax 613-998-6413, e-mail Jo-Anne_Doherty@hc-sc.gc.ca 
diseases. The list of diseases for national surveillance that resulted from the 1988 priority setting exercise remained unchanged until the second iteration, with the exception of hepatitis C, which was added in 1991, and a more extensive breakdown for syphilis in 1992.

Several new diseases were proposed for addition to the existing list; these included HIV, laboratory-confirmed influenza, Creutzfeld-Jacob disease (CJD), invasive pneumococcal disease, cryptosporidiosis, invasive group A streptococcal disease, hantavirus pulmonary syndrome, group B streptococcal disease in neonates, acute flaccid paralysis, cyclosporiasis, Reye syndrome, Lyme disease and hemolytic uremic syndrome.

The first iteration of the priority setting process for diseases under national surveillance was undertaken in 1988 (4-6). This paper provides an overview of the second iteration of the priority setting exercise undertaken in 1997 and 1998. The subcommittee established 10 criteria to measure the importance of each disease. Each criterion was assigned a score from 0 to 5 points based on the subcommittee's consensus. The majority of the criteria had a scoring schema of $0,1,3$ and 5 . The exceptions included 'incidence' with a scoring schema of $0,1,2$, 3, 4 and 5; 'severity' and 'socioeconomic burden' with a scoring schema of 1,3 and 5. The following is a brief description of each of the 10 criteria and the points awarded.

\section{INTERNATIONAL CONSIDERATIONS}

The World Health Organization (WHO) is interested in all communicable diseases to some extent; however, cholera, plague and yellow fever are subject to international health regulations. Canada must collect and report information about cases of these diseases as an international duty. Five points were awarded to the three diseases. Five points were awarded to measles because of the provincial and territorial commitment to eliminate measles in Canada by the year 2005 , and to poliomyelitis and acute flaccid paralysis because of the global polio eradication initiative.

\section{OTHER SECTOR INTEREST}

'Other sector interest' is defined as the importance of 'other sector involvement' in disease control. The factor is divided into three levels: high, moderate and low. A score of 0 is assigned if the disease is not influenced by 'other sector involvement'. HIV was awarded a score of 5 to reflect the work of the Canadian Blood Services, whereby HIV-contaminated blood has been excluded from the donor supply, virtually eliminating transmission by this route. The subcommittee gave 3 points to diseases directly prevented by the work of Agriculture Canada, environmental agencies, the Canadian Food Inspection Agency and other federal food regulatory agencies to control foodborne and waterborne diseases by the inspection of animals and food production facilities.

\section{INCIDENCE}

Incidence is defined as the number of new cases reported each year, and is calculated as a five-year average for the time interval, 1992 to 1996 . The variable is classified into quintiles and assigned 1 through 5 points: a score of 1 is assigned to cases which number 1 to 2999 cases/year; a score of 2 is assigned when the incidence is 3000 to 5999 cases/year; a score of 3 when the incidence is 6000 to $8999 /$ year; 4 points are assigned when the incidence is 9,000 to $11,999 /$ year, and 5 points are assigned when the number of cases reported equals or exceeds 12,000/year. Zero points are assigned if no cases have been reported. Chickenpox and genital chlamydia were each assigned 5 points.

\section{SEVERITY}

Severity is defined as 'most likely outcome' and classified into three groups. One point is assigned to the disease if it is of short duration and the patient completely recovers. Five points are assigned if the most likely outcome is death; for example, HIV, AIDS and rabies were each assigned a score of 5 .

\section{POTENTIAL TO SPREAD TO THE GENERAL POPULATION}

A score of $O$ is assigned to a disease if there is no potential threat of spread to the general population. A score of 1 is assigned if the potential for spread is localized and managed on a case-by-case basis. A score of 3 is assigned for 'local' outbreaks, and a score of 5 is assigned if the outbreak is national. For example, influenza, measles and chickenpox were each assigned 5 points. HIV was assigned 3 points, rabies was assigned 1 point and CJD was assigned 0 points.

\section{SOCIOECONOMIC BURDEN}

Socioeconomic burden is defined as the global cost per case'. The subcommittee considered factors such as the cost of immunization and food inspection programs, nonhospital health care, and long term disability. Economic impact analyses are not available for many communicable diseases, so subjective comparison was often necessary. The variable is classified into three groups: low is assigned a score of 1 ; medium has a score of 3; and 'high socioeconomic burden' is given a score of 5. Chickenpox and salmonellosis were assigned a 'low' score; influenza was designated 'medium', and HIV was assigned a 'high socioeconomic burden'.

\section{PREVENTABILITY}

Preventability is defined as the feasibility of a public health process to prevent or control the disease in question. A score of $O$ is assigned if there is no potential for public health intervention. A score of 1 is awarded if the disease incidence can be modified by educational program or behavioural modification. A score of 5 is awarded to those diseases that are preventable by vaccination. CJD and invasive group A streptococcal disease were each awarded a score of 0 . Several of the foodborne and waterborne diseases were awarded a score of 1 , reflecting the impact of educational material on safe food practices and the nonexistence of national strategies or programs for primary source control. HIV and AIDS were each awarded a score of 1 to reflect educational material on 'safer sex'. The sexually transmitted diseases, such as genital chlamydia, gonorrhea and syphilis, were assigned a score of 3 , reflecting the role of contact tracing as a public health intervention. 


\section{POTENTIAL TO DRIVE PUBLIC HEALTH POLICY}

The definition of 'potential to drive public health policy' implies that other criteria of incidence, severity, risk perception and preventability should be considered in determining the potential to drive public health policy. The factor is divided into three levels: 'low' with a score of 1 ; 'medium' with a score of 2; and 'high' with a score of 3. A score of 0 is assigned if the disease has no potential to influence public health policy. For instance, a score of 0 was assigned to yellow fever, cholera, malaria and leprosy. The highest score of three was awarded to HIV, AIDS, laboratory-confirmed influenza, tuberculosis, hepatitis $A$ and C, CJD, invasive pneumococcal disease and salmonellosis.

\section{RISK PERCEPTION}

Risk perception is defined as the current level of concern of the general population or the media, or the disease's potential to invoke a crisis. The assignment of scores is based on subcommittee members' experience and the population's perception of the problem. It includes the consideration of the following factors: immediate versus delayed effects of the infection; dreaded versus familiar disease; the mechanism of disease is not known or understood; involuntary children at risk; identifiable victims; lack of belief in authority of the information source; and the degree of media attention. This criterion is classified into three groups: 'low' with a score of 1 , 'moderate' with a score of 3 and 'high' with a score of 5. HIV, AIDS, rabies, invasive meningococcal disease, and invasive group A streptococcal disease were each assigned a score of 5.

\section{APPEARING TO OR CHANGING PATTERNS OVER THE PAST FIVE YEARS}

The criterion, 'appearing to or changing patterns over the past five years', is classified into three groups. A score of 0 indicates that the disease has been stable over the five-year period. A score of 1 is assigned to diseases that exhibited 'slow changes', a score of three is assigned to diseases with 'moderate changes over time', and a score of 5 is assigned to diseases that have shown 'dramatic changes'. No disease was assigned a score of 5. A score of 3 was assigned to HIV, AIDS, laboratory-confirmed influenza, tuberculosis, measles, pertussis, hepatitis $\mathrm{C}$, invasive pneumococcal disease, salmonellosis, hepatitis A, cryptosporidiosis, cyclosporiasis and malaria.

\section{DISCUSSION}

It is vital to emphasize that what is important in this exercise is not the absolute number of points given to a disease, but rather the relative position of the disease to others, and the cut-off point chosen. After ranking the scores, the subcommittee chose a cut-off of 13 points to recommend a disease for national surveillance. This decision was based on the experience of the raters with regards to the practical considerations of time, effort and money.

The results of the priority-setting exercise are presented in Table 1 . The diseases on this list constitute the list of diseases that are under national surveillance; reporting of these dis-
TABLE 1

Results of priority setting exercise for communicable diseases under national surveillance, Canada, 1988 and 1998

\begin{tabular}{|c|c|c|}
\hline Rank & 1988 disease & 1998 disease* $^{*}$ \\
\hline 1 & Measles & HIV \\
\hline 2 & Tuberculosis & AIDS \\
\hline 3 & AIDS & Laboratory confirmed influenza \\
\hline 4 & Hepatitis B & Tuberculosis \\
\hline 5 & Pertussis & Measles \\
\hline 6 & Salmonellosis & Rabies \\
\hline 7 & $\begin{array}{l}\text { Rubella and congenital } \\
\text { rubella syndrome }\end{array}$ & Pertussis \\
\hline 8 & $\begin{array}{l}\text { Haemophilus influenzae } \\
\text { invasive disease }\end{array}$ & Invasive meningococcal disease \\
\hline 9 & Diphtheria & Hepatitis C \\
\hline 10 & Chickenpox & Botulism \\
\hline 11 & Meningococcal infection & Poliomyelitis \\
\hline 12 & Gonococcal infection & Creutzfeld-Jacob Disease \\
\hline 13 & Rabies & Diptheria \\
\hline 14 & Paralytic poliomyelitis & Rubella, congenital \\
\hline 15 & Syphilis & Invasive pneumococcal disease \\
\hline 16 & Botulism & Salmonellosis \\
\hline 17 & Hepatitis A & Hepatitis A \\
\hline 18 & Shigellosis & $\begin{array}{l}\text { Haemophilus influenzae } \\
\text { invasive disease }\end{array}$ \\
\hline 19 & Mumps & Hepatitis B (acute case) \\
\hline 20 & Giardiasis & Tetanus \\
\hline 21 & Typhoid & Chickenpox \\
\hline 22 & Tetanus & Genital chlamydia \\
\hline 23 & Plague & Gonorrhea \\
\hline 24 & Yellow fever & Cryptosporidiosis \\
\hline 25 & Cholera & $\begin{array}{l}\text { Invasive group A streptococcal } \\
\text { disease }\end{array}$ \\
\hline 26 & $\begin{array}{l}\text { Pneumococcal and other } \\
\text { meningitis }\end{array}$ & Verotoxigenic Escherichia coli \\
\hline 27 & Trichinosis & $\begin{array}{l}\text { Hantavirus pulmonary } \\
\text { syndrome }\end{array}$ \\
\hline 28 & Campylobacteriosis & $\begin{array}{l}\text { Group B streptococcal disease } \\
\text { in neonates }\end{array}$ \\
\hline 29 & Legionellosis & Shigellosis \\
\hline 30 & Amebiasis & Cyclosporiasis \\
\hline 31 & Brucellosis & Yellow fever \\
\hline 32 & Malaria & Rubella \\
\hline 33 & Paratyphoid & Malaria \\
\hline 34 & Leprosy & Leprosy \\
\hline 35 & & Campylosbacterosis \\
\hline 36 & & Acute flaccid paralysis \\
\hline 37 & & Typhoid \\
\hline 38 & & Syphilis \\
\hline 39 & & Plague \\
\hline 40 & & Brucellosis \\
\hline 41 & & Mumps \\
\hline 42 & & Cholera \\
\hline 43 & & Giardiasis \\
\hline
\end{tabular}

*Reporting of these disease is effective January 1, 2000 
eases is effective January 1, 2000. The 'top five' diseases were HIV, AIDS, laboratory-confirmed influenza, tuberculosis and measles. Of the 'newly proposed' diseases, two did not make the list: Reye syndrome and hemolytic uremic syndrome. The subcommittee decided that Lyme disease and legionellosis require monitoring but on a 'need-to-know' basis. The following diseases from the current list did not make the cut-off point, and consequently, will no longer warrant national surveillance: 'meningitis, other bacterial', listeriosis, gonococcal opthalmia neonatorum, trichinosis, chancroid, 'meningitis, viral', and amoebiasis.

The United Kingdom's Public Health Laboratory Service (PHLS) recently undertook a priority setting exercise using six criteria: present burden of ill health social and economic impact; potential threats; health gain opportunity; public concern and confidence; and PHLS-added value (7). A more in-depth analysis comparing the PHLS results with the results of the priority setting exercise described in this paper is forthcoming.

Disease surveillance is much more than collecting numbers $(8,9)$. It also means compilation, consolidation and analysis of data, and making conclusions. Provincial epidemiologists and the LCDC have attempted to meet this challenge by developing standardized case definitions for the notifiable diseases, instituting case-by-case disease reporting to the federal level and defining a core set of variables for each case reported.

The members of the subcommittee should be commended for their diligence in undertaking the priority setting exercise.
Communicable disease surveillance in Canada will benefit from their task; the information collected will lead to action which, in turn, will improve the health of all Canadians. The partnership between the provinces and territories, and the LCDC will continue the information exchange to form the foundation of a national communicable disease strategy.

ACKNOWLEDGMENTS: We gratefully acknowledge the role of Dr Paul Sockett in initiating the priority setting exercise.

\section{REFERENCES}

1. Statistics Act. 1970-71-72, c15, s1.

2. Department of National Health and Welfare Act. Revised Statutes of Canada $1985 ; \mathrm{cN} 9, \mathrm{~s} 1$.

3. Giesecke J. Choosing diseases for surveillance. Lancet 1999;353:344.

4. Carter A. National Advisory Committee on Epidemiology Subcommittee. Establishing goals, techniques and priorities for national communicable disease surveillance. Can J Infect Dis 1991;2:37-40.

5. Carter AO. Setting priorities: The Canadian experience in communicable disease surveillance. MMWR Morb Mortal Wkly Rep 1992:41(Suppl):79-84.

6. Establishing goals, techniques and priorities for national communicable disease surveillance. Can Dis Wkly Rep 1991;17:79-84.

7. Rushdy A, O'Mahony M. PHLS overview of communicable diseases 1997: results of a priority setting exercise. Commun Dis Rep CDR Suppl 1998;8:S1-12.

8. Sockett PN, Garnet M-J, Scott C. Communicable disease surveillance: Notification of infectious diseases in Canada. Can J Infect J 1996;7:293-5.

9. Sockett PN. Communicable disease surveillance: Strengthening the national perspective. Can J Infect Dis 1995;6:165-8. 


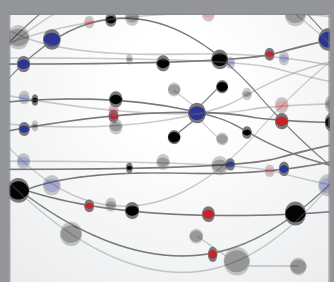

The Scientific World Journal
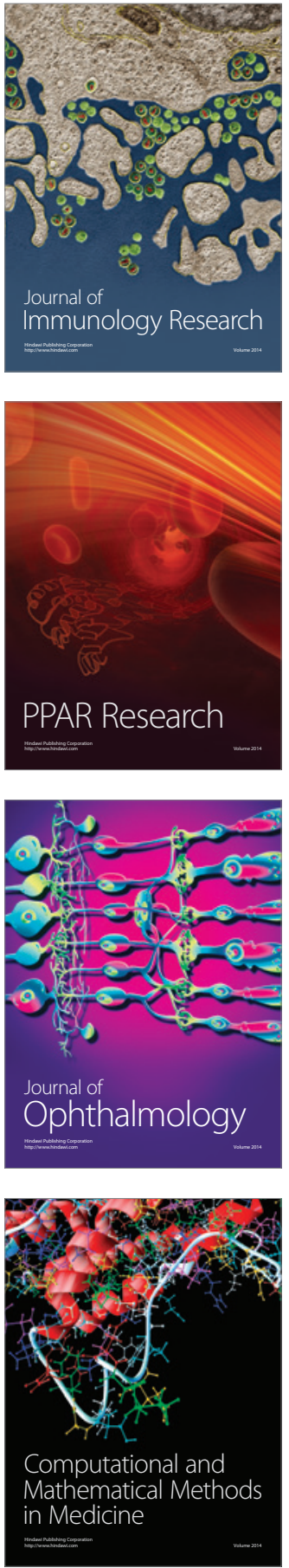

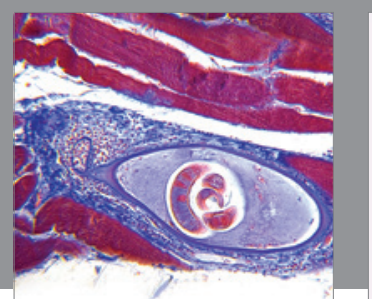

Gastroenterology Research and Practice

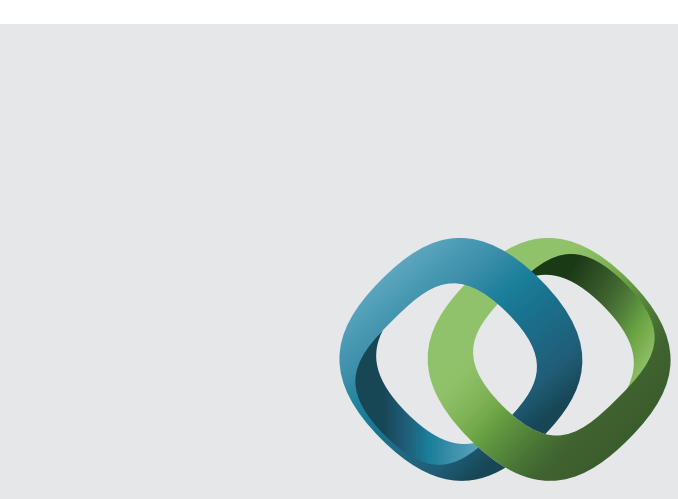

\section{Hindawi}

Submit your manuscripts at

http://www.hindawi.com
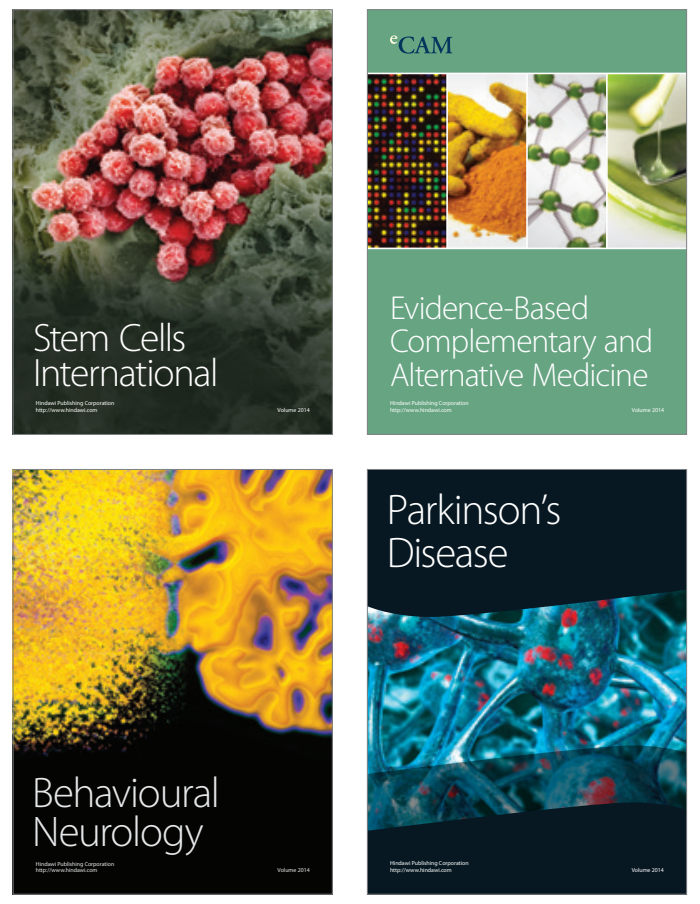
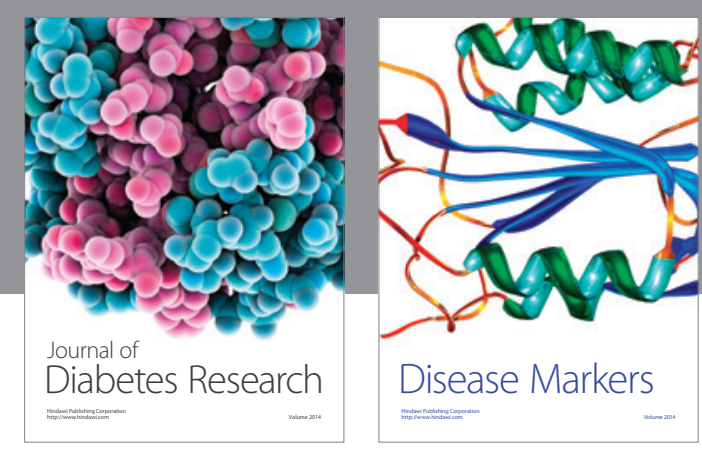

Disease Markers
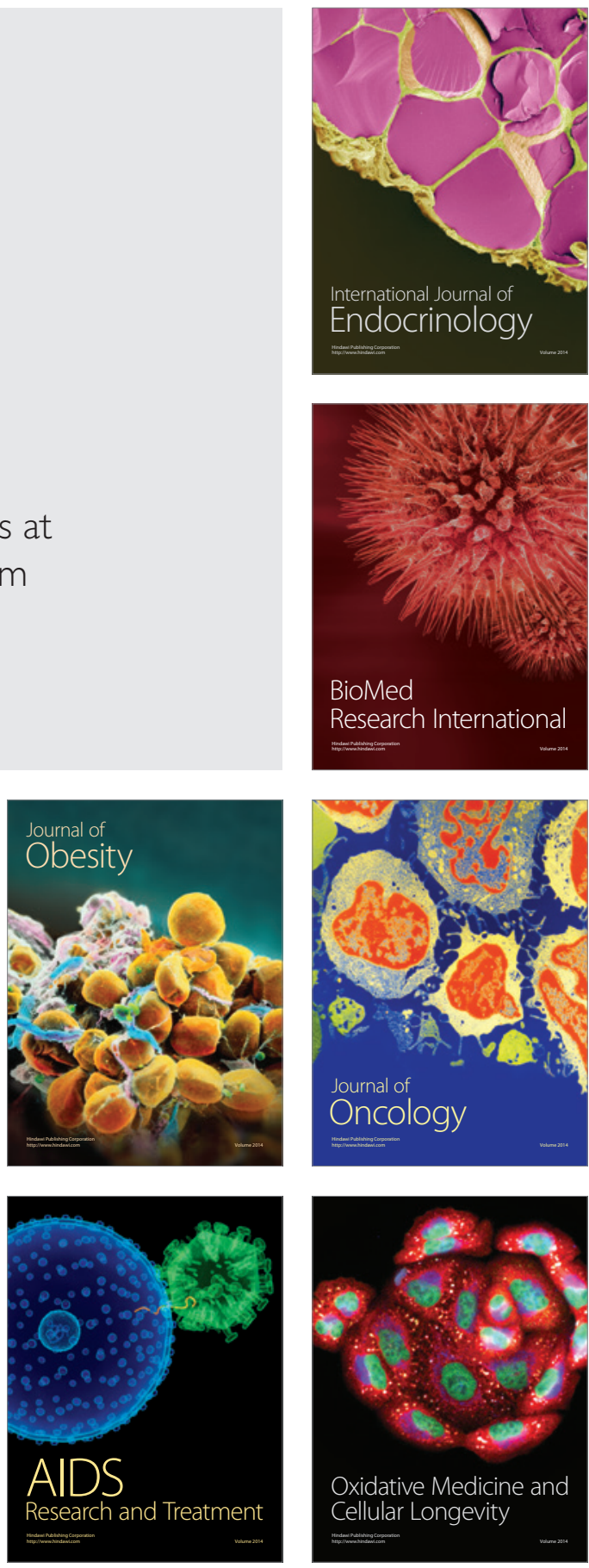